\title{
The Thyroid Hormone Receptor-RUNX2 Axis: A Novel Tumor Suppressive Pathway in Breast Cancer
}

\author{
Eric L. Bolf ${ }^{1,2}$ • Noelle E. Gillis ${ }^{1,2}$ - Michael S. Barnum ${ }^{1} \cdot$ Caitlin M. Beaudet $^{1} \cdot$ Grace Y. Yu $^{1}$ • Jennifer A. Tomczak ${ }^{1}$. \\ Janet L. Stein ${ }^{2,3}$ - Jane B. Lian ${ }^{2,3} \cdot$ Gary S. Stein $^{2,3}$ • Frances E. Carr ${ }^{1,2}$ (D)
}

Received: 18 October 2019 / Accepted: 25 November 2019 / Published online: 21 December 2019

(C) Springer Science+Business Media, LLC, part of Springer Nature 2019

\begin{abstract}
Metastatic breast cancer is refractory to conventional therapies and is an end-stage disease. RUNX2 is a transcription factor that becomes oncogenic when aberrantly expressed in multiple tumor types, including breast cancer, supporting tumor progression and metastases. Our previous work demonstrated that the thyroid hormone receptor beta (TR $\beta$ ) inhibits RUNX2 expression and tumorigenic characteristics in thyroid cells. As TR $\beta$ is a tumor suppressor, we investigated the compelling question whether TR $\beta$ also regulates RUNX2 in breast cancer. The Cancer Genome Atlas indicates that TR $\beta$ expression is decreased in the most aggressive basal-like subtype of breast cancer. We established that modulated levels of TR $\beta$ results in corresponding changes in the high levels of RUNX2 expression in metastatic, basal-like breast cells. The MDA-MB-231 triple-negative breast cancer cell line exhibits low expression of TR $\beta$ and high levels of RUNX2. Increased expression of TR $\beta$ decreased RUNX2 levels. The thyroid hormone-mediated suppression of RUNX2 is TR $\beta$ specific as TR $\alpha$ overexpression failed to alter RUNX2 expression. Consistent with these findings, knockdown of TR $\beta$ in non-tumor MCF10A mammary epithelial-like cells results in an increase in RUNX2 and RUNX2 target genes. Mechanistically, TR $\beta$ directly interacts with the proximal promoter of RUNX2 through a thyroid hormone response element to reduce promoter activity. The TR $\beta$ suppression of the oncogene RUNX2 is a signaling pathway shared by thyroid and breast cancers. Our findings provide a novel mechanism for TR $\beta$-mediated tumor suppression in breast cancers. This pathway may be common to many solid tumors and impact treatment for metastatic cancers.
\end{abstract}

Keywords Breast Cancer $\cdot$ Thyroid hormone $\cdot$ RUNX2 $\cdot$ Gene expression

\section{Introduction}

Breast cancer is the most commonly diagnosed malignancy in women worldwide [1]. In the USA, one in eight women is expected to develop the disease over the course of their

Electronic supplementary material The online version of this article (https://doi.org/10.1007/s12672-019-00373-2) contains supplementary material, which is available to authorized users.

Frances E. Carr

frances.carr@med.uvm.edu

1 Department of Pharmacology, University of Vermont, 89 Beaumont Avenue, Burlington, VT 05405, USA

2 University of Vermont Cancer Center, Larner College of Medicine, University of Vermont, 89 Beaumont Avenue, Burlington, VT 05405, USA

3 Department of Biochemistry, University of Vermont, Burlington, VT 05405, USA lives [2]. Endocrine therapies that target the estrogen receptor $(\mathrm{ER} \alpha)$ are a cornerstone of breast cancer treatment for most patients. Yet, these therapies often fail, as a consequence of distinct resistance pathways. Non-steroid nuclear hormone receptors have emerged as diagnostic and therapeutic targets in breast cancer, yet the functional mechanistic and clinically relevant roles of most of this family are minimally understood [3]. Notably, several lines of evidence from gain of function experiments indicate that thyroid hormone receptor beta (TR $\beta$ ) exhibits tumor suppressor activity in breast cancer. In luminal A MCF7 cells, re-expression of TR $\beta$ reduced xenograft tumor mass and pro-oncogenic STAT3 signaling [4]. Similar results were observed in triple-negative MDA-MB-468 cells. TR $\beta$ expression reduced metastases and angiogenesis [5]; further, expression of TR $\beta$ repressed PI3K signaling and induced apoptosis [6]. Additionally, TR $\beta$ is correlated with improved disease-free survival in both BRCA-associated tumors and in triplenegative breast cancer $[7,8]$. This may be in part due to 
increased sensitization to chemotherapeutics [8], necessitating a thorough understanding of the mechanisms by which TR $\beta$ suppresses tumor growth.

TR $\beta$ also exhibits tumor suppressor activity in thyroid cancer [9], a disease with a link to breast cancer. Women who develop thyroid cancer are more likely to develop breast cancer as a second primary tumor, and patients with breast cancer are at increased risk of developing thyroid cancer [10-13]. Further understanding of either of these tumor types may reveal important insights into the predisposition for the other disease as well as insights into how both tumor types develop. Reciprocal synergies between these tumors may be highly informative. Intriguingly, the bone is one of the most common distal sites of metastases in breast cancer [14] and is the second most common site in thyroid metastases [15]. We recently established a novel tumor suppression pathway by which the master regulator of osteoblast development, RUNX2, which functions oncogenically in cancer and promotes invasion and metastasis in thyroid cancer $[16,17]$, is repressed by TR $\beta$ in thyroid cells $[18,19]$. Addition of the ligand, triiodothyronine $\left(T_{3}\right)$, enhances the TR $\beta$-mediated transcriptional events, reinforcing this novel pathway. In breast cancer, RUNX2 drives tumor progression, promoting proliferation and distal metastasis $[20,21]$ in part through the upregulation of genes critical to the process of invasion, including VEGF, OPN, and matrix metalloproteases (MMPs) [17, 22-26]. These findings indicate that the $\mathrm{T}_{3}$-TR $\beta$-RUNX2 pathway could be active in breast cancer as well as in thyroid cancer.

Unlike in thyroid cells where the dominant thyroid hormone receptor is $\mathrm{TR} \beta$, in breast cells $\mathrm{TR} \alpha$ expression is robust. Although not yet well defined, $\mathrm{TR} \alpha$, in contrast to $\operatorname{TR} \beta$, may be associated with breast tumorigenesis. High $\mathrm{TR} \alpha$ expression in BRCAl-associated breast tumors correlates with a poor prognosis [7]. It has been reported that elevated levels of the splice variant $T R \alpha 1$ of $T R \alpha$ are associated with a poor prognosis and decreased patient survival [27].

A compelling question is whether the TR $\beta$-RUNX2 signaling is active in breast as well as thyroid cancer. Given that $\mathrm{T}_{3}$ activates both $\mathrm{TR} \beta$ and $\mathrm{TR} \alpha$, and that $\mathrm{TR} \alpha$ expression is robust in breast cancer cells, our experimental strategy was to determine whether one or both TRs are responsible for repression of RUNX2 in breast cancer cells. Our results establish that TR $\beta$ suppresses the oncogenic RUNX2 activity in breast cancer cells. These findings demonstrate that the suppressive action of $T_{3}$ is mediated through TR $\beta$ but not TR $\alpha$ and support mechanistic linkage of thyroid hormone control with breast cancer activation and repression as well as provide potential therapeutic targets that are based on selective modifications in thyroid hormone receptor relationships.

\section{Materials and Methods}

Cell Culture and Treatments MCF10A cells were grown in DMEM/F-12 (1:1) (Hyclone), supplemented with 5\% horse serum (Gibco), human insulin $(10 \mu \mathrm{g} / \mathrm{ml})$, human EGF $(20 \mathrm{ng} / \mathrm{ml})$, cholera toxin $(100 \mathrm{ng} / \mathrm{ml})$, hydrocortisone $(0.5 \mu \mathrm{g} / \mathrm{ml})$, and L-glutamine (2 mM) (Millipore Sigma). MDA-MB-231 was maintained in $\alpha$ MEM supplemented with $10 \%$ fetal bovine serum (Life Technologies) and L-glutamine $(2 \mathrm{mM})$. Both cell lines were grown in the presence of penicillin-streptomycin (200 IU/L) (Cellgro/Mediatech). Cells were maintained at $37{ }^{\circ} \mathrm{C}, 5 \% \mathrm{CO}_{2}$, and $100 \%$ humidity. For hormone and drug treatments, cells were maintained in charcoal-stripped serum (Sigma). MCF10A and MDA-MB231 cells were purchased from the American Type Culture Collection and authenticated via short tandem repeat analysis in January 2018.

Transient Transfections and Cloning Transfections were performed using Lipofectamine 3000 (Thermo Scientific) following manufacturer's directions. The pDEST515-FLAG-THRB plasmid is used in the same prior work, as was the negative control vector [18]. We cloned pDEST515-FLAG-THRA using MCF10A cDNA (Supplementary Table 1). The amplicon was purified from an agarose gel with the Monarch ${ }^{\circledR} \mathrm{Gel}$ Extraction Kit (New England Biolabs), and both the pDEST515-FLAG-THRB backbone vector and the THRA amplicon were digested with HindIII and BamHI (New England Biolabs). The THRB cds dropped out from the backbone, and the THRA cds corresponding to the TR $\alpha 1$ variant was ligated into the vector. The identity of pDEST515-FLAGTHRA was confirmed by Sanger sequencing.

Immunoblot Proteins were isolated from whole cells in lysis buffer (20 mM Tris-HCl, pH 8, $137 \mathrm{mM} \mathrm{NaCl}, 10 \%$ glycerol, $1 \%$ Triton X-100, and 2 mM EDTA) containing Halt Protease Inhibitor Cocktail (Thermo Scientific 78,410) as previously described [19]. Nuclear proteins were prepared with NE-PER nuclear and cytoplasmic extraction reagents (Thermo Scientific 78,833) per manufacturer's protocol. Proteins were resolved by polyacrylamide gel electrophoresis on Novex $10 \%$ Tris-glycine gels (Invitrogen) and immobilized onto Protran nitrocellulose membranes (GE Healthcare) by electroblot (Bio-Rad Laboratories). Specific proteins were detected by immunoblotting with the indicated antibodies (Supplementary Table 2). Immunoreactive proteins were detected by enhanced chemiluminescence (GE Healthcare), visualized by VersaDoc MP3000 (Bio-Rad Laboratories), and intensities were quantified by Image Lab (Bio-Rad Laboratories).

RNA Extraction and Quantitative Real-Time PCR (qRT-PCR) The total RNA was extracted using RNeasy Plus Kit (Qiagen) according to manufacturer's protocol. cDNA was 
then generated using 5X RT Mastermix (ABM). Gene expression was quantified by qRT-PCR using $2 \mathrm{X}$ BrightGreen Mastermix (ABM) on a QuantStudio 3 real-time PCR system (Applied Biosystems). Primers are indicated in Supplementary Table 1. Fold change in gene expression compared to endogenous control GAPDH was calculated using the ddCT method.

siRNA Transfection A loss of function was assayed by siRNA using on-target plus siRNAs targeting human TR $\beta$ (L-003447-00) with non-targeting siRNA (D-001810-10-20; GE Healthcare Dharmacon) as a control. Cells were plated at a density of $2.5 \times 10^{5}$ per well and transfected with 50-200 nM siRNA with oligofectamine, as per manufacturer's protocol (Invitrogen/Life Technologies). The effect of the knockdown of TR $\beta$ on endogenous RUNX2 and metastatic markers was determined after $24 \mathrm{~h}$.

Chromatin Immunoprecipitation (ChIP) Binding to RUNX2 chromatin was determined by ChIP-PCR. Cultured human breast cells were cross-linked with $1 \%$ formaldehyde for $10 \mathrm{~min}$, neutralized with $125 \mathrm{mM}$ glycine, rinsed twice with PBS, pelleted, and frozen. Cells were lysed in the presence of protease inhibitors (Roche), and chromatin was extracted and sonicated to $200-500$ bp in size using a Covaris S220 Focused Ultrasonicator. Sonicated cell lysate was incubated with $2 \mu \mathrm{g}$ of indicated antibody (Supplementary Table 2) and rotated overnight at $4{ }^{\circ} \mathrm{C}$. Around 20 microliters of Protein G Dynabeads (Invitrogen) were blocked in $0.5 \%$ BSA and resuspended in lysis buffer, added to the lysate/antibody mix, and rotated at $4{ }^{\circ} \mathrm{C}$ for $3 \mathrm{~h}$. Complexes were washed extensively, eluted, and incubated at $65{ }^{\circ} \mathrm{C}$ overnight to reverse cross-links. Samples were treated with ribonuclease A, incubated with proteinase $\mathrm{K}$, phenol/chloroform extracted, and ethanol precipitated. Pellets were re-suspended in $70-\mu \mathrm{L} 10-$ $\mathrm{mM}$ Tris- $\mathrm{HCl}, \mathrm{pH} 8$. Fold binding over IgG was determined by qRT-PCR.

Reporter Assay Constructs were described in a prior publication [19]. We co-transfected the -763 to -16 pGL3 luciferase reporter plasmid with pDEST515-FLAG-THRB in MCF10A and MDA-MB-231 cells and recorded luminescence after $48 \mathrm{~h}$ as previously described. SV40 renilla construct was omitted due to reports of functional thyroid hormone response elements (TRE) [28].

DNA Pulldown Assay The assay performed was as described in a published protocol with the following optimizations [29]. MyOne T1 streptavidin beads (Invitrogen) were rinsed twice with binding buffer (20 mM HEPES, $30 \mathrm{mM} \mathrm{KCl}, 1 \mathrm{mM}$ EDTA, $10 \mathrm{mM}\left(\mathrm{NH}_{4}\right)_{2} \mathrm{SO}_{4}, 1 \mathrm{mM}$ DTT, $0.2 \%(\mathrm{v} / \mathrm{v})$ Tween$20, \mathrm{pH}$ 7.6), incubated with $5 \mathrm{ng}$ of biotinylated probe at $4{ }^{\circ} \mathrm{C}$ for $1 \mathrm{~h}$, and then washed twice with binding buffer. Around
$350 \mu \mathrm{g}$ of nuclear protein extract was precleared with beads and $8 \mu \mathrm{g}$ of sheared herring sperm DNA (Promega) for $15 \mathrm{~min}$ at room temperature. The lysate was combined with the probebound beads. Volume was brought to $0.75 \mathrm{ml}$ with wash buffer (20 mM Tris-HCl, $150 \mathrm{mM} \mathrm{NaCl}, 1 \mathrm{mM}$ EDTA, $0.5 \%$ (v/v) $\mathrm{NP}-40, \mathrm{pH} 7.5$ ), and $\mathrm{KCl}$ was added to a final concentration of $300 \mathrm{mM}$ for incubation at $4{ }^{\circ} \mathrm{C}$ for $1.5 \mathrm{~h}$. The beads were then washed three times with wash buffer, once with water, and proteins were eluted for immunoblot.

Statistics All statistical analyses were performed using GraphPad Prism software. Unless otherwise indicated, an unpaired T-test $(p<0.05)$ was used for comparisons between two sets, a two-way ANOVA followed by a multiple comparisons test $(\mathrm{p}<0.05)$ was used to compare groups, and data are represented as means \pm standard deviation.

\section{Results}

\section{TR Expression Is Reduced in Aggressive Breast Cancer}

Basal-like breast tumors exhibit elevated expression of RUNX2 [30]. We have previously reported an inverse relationship between TR $\beta$ and RUNX2 in thyroid cancer, providing a basis for the compelling question if a similar dynamic relationship is present in breast cancer. Both TR $\alpha$ and TR $\beta$ are both expressed in normal breast tissue [31], necessitating examination of the expression levels for the THRA and THRB genes. We interrogated RNA expression data from the Cancer Genome Atlas PanCancer Atlas using the cBioPortal interface $[32,33]$ (Fig. 1). THRB was significantly repressed in the most aggressive basal-like tumors compared to other molecular subtypes. THRA expression was strikingly reduced in the basal-like breast tumors, although there was also increased expression of THRA in HER2-positive tumors. Similar to $T H R B, T H R A$ expression does not vary significantly in the differentiated normal-like, luminal A, and luminal B cancers. In conclusion, the most aggressive basal-like breast cancers exhibit the lowest expression of both TRs.

\section{Thyroid Hormone Repression of RUNX2 Is Driven by TR $\beta$}

MCF10A mammary epithelial-like cells and MDA-MB-231 triple-negative breast cancer cells were examined to determine whether treatment with $\mathrm{T}_{3}$ can modify RUNX2 expression. Following $24 \mathrm{~h}$ of treatment with $10^{-8} \mathrm{M}$ of $\mathrm{T}_{3}$ to model euthyroid serum conditions, RNA was isolated from the cells for analysis by qPCR and protein for immunoblot analysis. $\mathrm{T}_{3}$ treatment significantly decreased $R U N X 2 \mathrm{mRNA}$ and protein levels in both cell lines after $24 \mathrm{~h}$ (Fig. 2 and Fig. S1). 

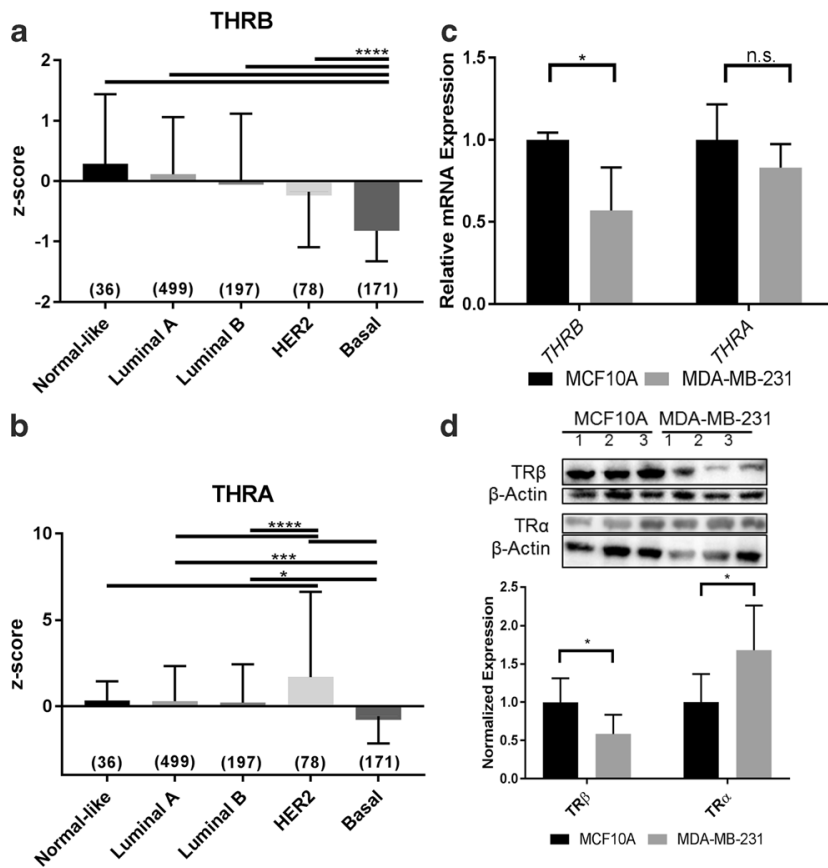

d

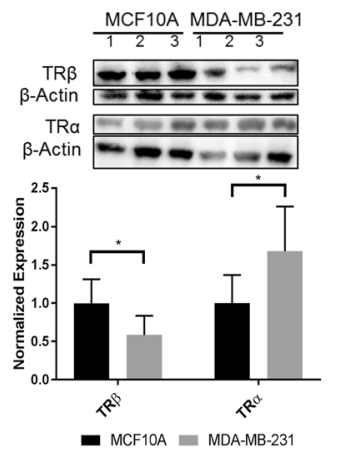

Fig. 1 Baseline expression of thyroid hormone receptors and RUNX2 in breast cells. (a) THRB RNA expression is significantly reduced in basallike breast tumors in comparison to all other subtypes. (b) THRA RNA expression is significantly repressed in basal-like breast cancers and greatest in HER2 expressing tumors. Other significant differences are indicated in the figure. (c) MCF10A expresses higher levels of THRB mRNA than MDA-MB-231 $(n=4, p<0.05)$. Both MCF10A and MDA-MB-231 express comparable THRA mRNA $(\mathrm{n}=4, p>0.05)$. (d) MCF10A expresses greater levels of TR $\beta$ protein than MDA-MB-231, while MDA-MB-231 expresses greater levels of TR $\alpha$ protein than MCF10A cells as measured by immunoblot $(n=6, p<0.05)$. $* p<0.05, * * * p<0.001, * * * * p<0.0001$, n.s. not significant

Unlike in the thyroid cells where we previously characterized the action of $\mathrm{T}_{3}$ on expression of the RUNX2 gene, breast cells express both TR $\alpha$ and TR $\beta$. The DNA-binding domain of TRs is highly conserved with significant homology between both TRs resulting in competency for both receptors to bind the same canonical response element on chromatin [34]; however there are genes that are selectively regulated by a single TR [35-37] likely reflecting different chromatin protein assembly. To evaluate whether one or both TRs can repress RUNX2 expression, MDA-MB-231 cells were transiently transfected with vectors that overexpress either $\mathrm{TR} \alpha$ or TR $\beta$. When RUNX2 protein was quantitated by immunoblot analysis, TR $\beta$ expression was observed to reduce RUNX2 levels. However, when cells were transfected with a TR $\alpha$ expression vector, RUNX2 levels did not change (Fig. 3). To determine whether TR $\alpha$ could act as a negative regulator of TR $\beta, T R \alpha$ was also overexpressed in MCF10A cells, which robustly express TR $\beta$. No change to RUNX2 expression was observed, showing that increased levels of $\mathrm{TR} \alpha$ did not inhibit the suppressive activity of TR $\beta$. These results provide a functional indication of the specificity for TR $\beta$ regulation of RUNX2 in breast cancer.
To confirm that TR $\beta$ can repress RUNX2, TR $\beta$ expression was knocked down by siRNA in the normal breast cell line MCF10A (Fig. 4). Decreased levels of TR $\beta$ increased RUNX2 expression, and we also observed a significant increase in expression of the RUNX2-upregulated genes CCND1 [38], $M M P 9$ [22], and VEGFA [24, 25] after siRNA knockdown of TR $\beta$. Importantly, each of these have a demonstrated role in the process of tumorigenesis. These results reinforce the TR $\beta$ repression of RUNX2 expression with the functional consequence of repressing RUNX2-driven pro-tumorigenic activity.

\section{TR $\beta$ Binds to the RUNX2 Promoter}

We previously mapped TREs in the P1 promoter of the RUNX2 gene and demonstrated that TR $\beta$ directly interacts with these regions in thyroid cells [19]. Following ChIP from MCF10A cells, there was significant enrichment of the $R U N X 2$ promoter utilizing a TR $\beta$ antibody as compared to IgG control (Fig. 5A). This was further validated by a DNA pulldown assay utilizing biotinylated oligonucleotides containing a previously characterized TRE. Incubation of this oligonucleotide with MCF10A lysate revealed TR $\beta$ binding, which was ablated when the TRE was mutated (Fig. 5B). Additionally, a luciferase reporter vector was co-transfected with a TR $\beta$ expression vector. Nominal but insignificant repression was observed in MCF10A, in contrast to the MDAMB-231 cells that express very low levels of endogenous TR $\beta$ where there was significant repression (Fig. 5C). Taken together, these data provide evidence for direct interaction between TR $\beta$ and the $R U N X 2$ gene to alter gene expression.
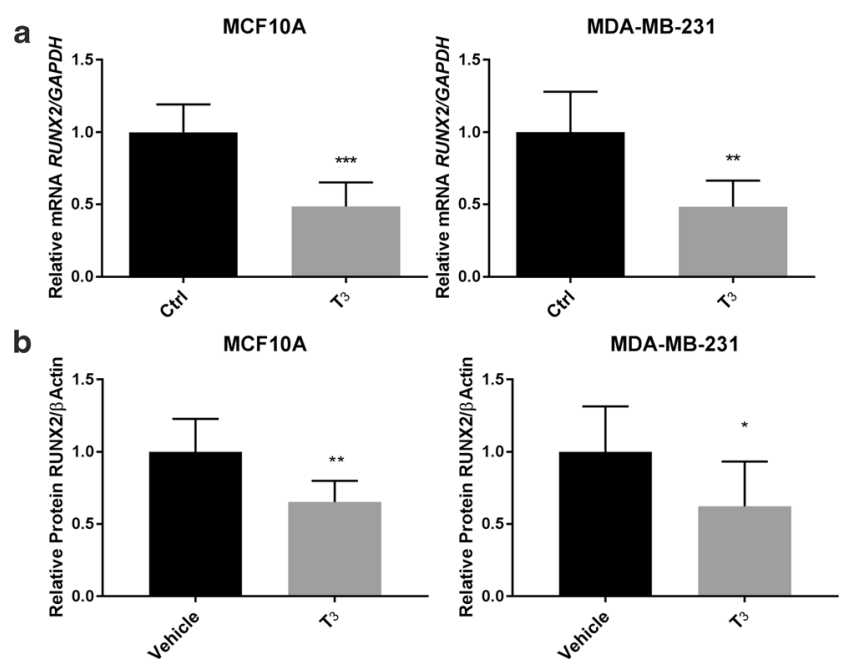

Fig. 2 RUNX2 expression is reduced by thyroid hormone treatment MCF10A and MDA-MB-231 were treated with $\mathrm{T}_{3}$ at $10^{-8} \mathrm{M}$ for $24 \mathrm{~h}$. (a) Expression of RUNX2 was measured by RT-qPCR (MCF10A, $n=6$, $p<0.001$; MDA-MB-231, $n=6, p<0.01$ ). (b) RUNX2 protein levels were determined by immunoblot (MCF10A, $n=9, p<0.01$; MDA-MB231, $n=9, p<0.05)$. $* p<0.05, * * p<0.01, * * * p<0.001$ 


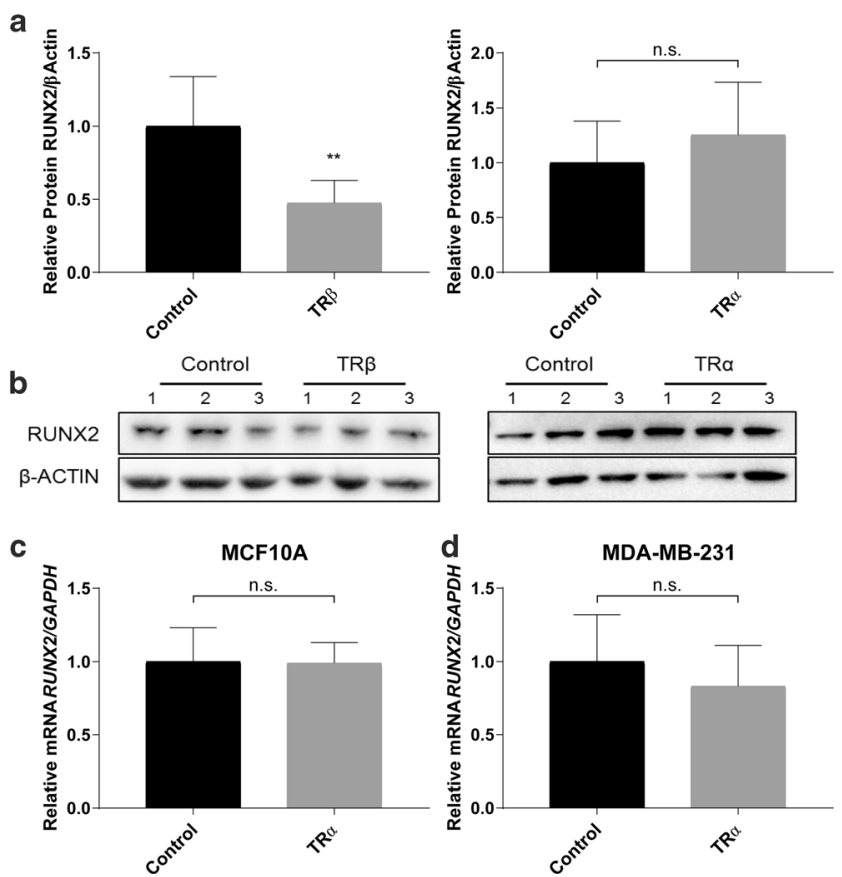

Fig. $3 \mathrm{TR} \beta$, and not TR $\alpha$, represses RUNX2. (a) Transient transfection into MDA-MB-231 cells of a plasmid encoding TR $\beta$ significantly reduced RUNX2 levels $(n=6, p<0.01)$; however, transfection with a $\mathrm{TR} \alpha$ vector did not significantly alter RUNX2 protein expression $(n=6$, $p>0.05$ ) with (b) representative immunoblots. Transient transfection of TR $\alpha$ did not alter $R U N X 2$ mRNA levels in (c) and MCF10A (d) MDAMB-231 cells. $* * p<0.01$, n.s. not significant

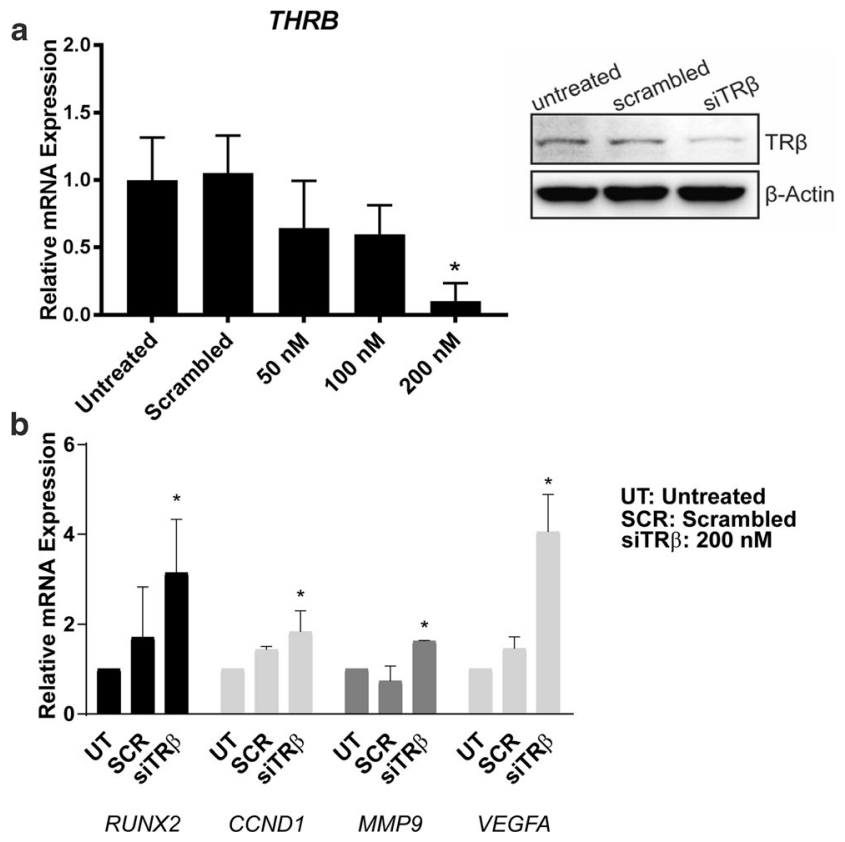

Fig. 4 Knockdown of THRB in MCF10A enhances RUNX2 and RUNX2 activity. (d) Treatment of MCF10A with siRNA against TR $\beta$ repressed its expression in the cells as confirmed by immunoblot. (b) Loss of TR $\beta$ mRNA correlated with significantly increased RUNX2 expression as measured by RT-qPCR $(n=6, P<0.05)$. There was also an observed increase in the RUNX2 upregulated genes CCND1 $(n=4)$, $\operatorname{MMP} 9(n=4)$, and VEGFA $(n=4) . * p<0.05$

\section{Discussion}

These results demonstrate that $\mathrm{T}_{3}$-mediated RUNX2 repression in breast cancer is facilitated by TR $\beta$ and not via TR $\alpha$. Importantly, we have identified a gene that is preferentially regulated by $\operatorname{TR} \beta$ and not TR $\alpha$. This specificity provides a mechanistic insight into the observed TR $\beta$ tumor suppressor role and the putative oncogenic role of $\operatorname{TR} \alpha$ [7]. We have also demonstrated a common pathway in breast and thyroid cancers, which demonstrates the value of this pathway for further understanding the observed epidemiological link between both diseases [10-13].

To understand the etiology of the link between breast and thyroid tumors, it is vital to understand the actions of shared tumor suppressors and oncogenes. The mechanisms by which $\operatorname{TR} \beta$ represses tumorigenesis is an important question in tumor biology and pathology but are minimally understood. Previously characterized mechanisms of TR $\beta$-mediated tumor suppression in breast cancer focused on regulation of the PI3K/Akt [39], Ras/MAPK [40], and JAK2-STAT3 [4] pathways and induction of mesenchymal-to-epithelial transitions [41]. In thyroid cancer, TR $\beta$ suppresses tumorigenesis through PI3K/Akt [42] and RUNX2 [19]. Our work here demonstrates that in addition to shared tumor suppression by PI3K/Akt, TR $\beta$ acts to repress RUNX2 expression in both cell types. The Ras/MAPK and JAK2-STAT3 pathways and epithelial characteristics are all features regulated by TR $\beta$ in breast cancer that merit further investigation in thyroid cancer. Revealing common features can aid in understanding the metachronous nature of the two diseases.

The $\mathrm{T}_{3}$-TR $\beta$-RUNX2 axis could be a common signaling pathway in a variety of cancers. In addition to the role of RUNX2 in breast and thyroid tumorigenesis, RUNX2 has been proposed to contribute to the development of prostate cancer [43], liver carcinoma [44], colon cancer [45], and melanoma [46]. TR $\beta$ and/or $T_{3}$ has been shown to have antitumor roles in these cancers as well. Overexpression of TR $\beta$ reduces cellular proliferation in vivo in hepatocellular carcinoma [5]. Thyroid hormone also induces differentiation of colon cancer stem cells [47]. In melanoma, a loss of heterozygosity of the THRB gene has been observed [48], which is consistent with functioning as a tumor suppressor gene, and $\mathrm{T}_{3}$ stimulation of dendritic cells represses melanoma tumor size in a xenograft [49]. These findings suggest that the $T_{3}$ TR $\beta$-RUNX2 signaling program may be operational in a spectrum of tissues.

This work expands the understanding for involvement of the TRs in tumorigenesis and is consistent with the potential for TRs to improve diagnostic or prognostic capabilities for cancer diagnosis and treatment responsiveness. Aside from the treatment of existing thyroid disorders or to alleviate side effects from therapeutics, direct modulation of thyroid hormone levels is undesirably as potential confounding effects 
a

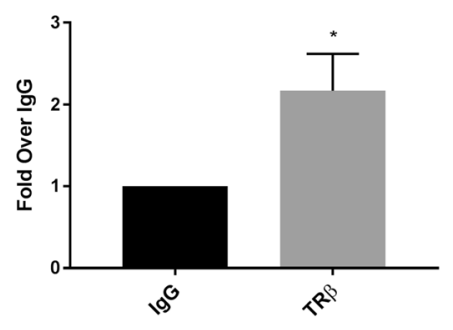

b

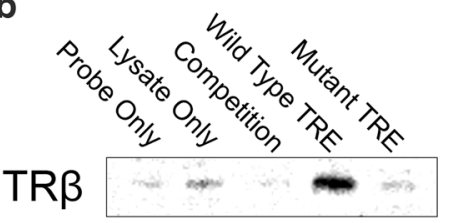

RUNX2P1

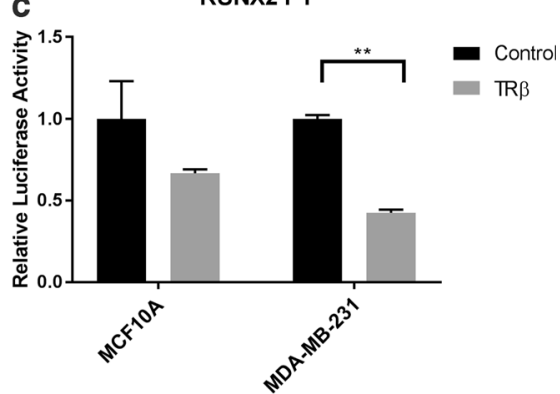

Fig. 5 TR $\beta$ binds to the RUNX2 promoter. (a) Chromatin immunoprecipitation-PCR of RUNX2 in MCF10A cells $(n=3, p<$ 0.05 ). (b) Biotinylated $R U N X 2$ proximal promoter successfully pulls down TR $\beta$ from MCF10A lysate as shown by immunoblot. Mutation of the TRE ablated this interaction. (c) Cotransfection of an expression vector and luciferase reporter vector in breast cell lines. Nominal repression of the promoter due to TR $\beta$ overexpression was observed in MCF10A $(n=2, P>0.05)$ and MDA-MB-231 showed significant repression $(n=2, p<0.01)$. $* p<0.05, * * p<0.01$ must be considered. TR $\alpha 1$ is associated with more advanced breast tumors [7, 27] and potential side effects for the cardiovascular system that includes tachycardia and hypertension which result from $\operatorname{TR} \alpha$ signaling in the heart [50]. Additionally, the $\alpha \mathrm{V} \beta 3$ integrin is responsive to thyroid hormones, primarily thyroxine, promoting pro-oncogenic activity through the MAPK pathway [51, 52], and through studies utilizing prostate cancer cells and osteoblasts, it was shown that $\alpha \mathrm{V} \beta 3$ induces an increase in expression and transcriptional activity of RUNX2 [53, 54]. However, it is not clear whether $\alpha \mathrm{V} \beta 3$ can regulate RUNX2 in response to thyroid hormones. Encouragingly, thyromimetic compounds have been developed as selective agonists to $\operatorname{TR} \beta[55,56]$ and may stimulate $\mathrm{TR} \beta$ tumor suppressor activity in cancer. There is an encouraging evidence that thyromimetics can enhance the sensitivity of aggressive breast cancer cells to certain chemotherapies [8]. Our work demonstrates another mechanism by which $\mathrm{TR} \beta$ pharmacological stimulation may be beneficial.

In closing, our findings demonstrate a tumor suppressive function of TR $\beta$ shared by multiple tissue types. The $T_{3}$-TR $\beta$-RUNX2 pathway is active in a variety of cancers. Understanding the role of this signaling in tumorigenesis may be leveraged for the development of novel clinical interventions with high specificity and minimal off-target consequences.

Acknowledgments The results published here are in whole or part based upon data generated by the TCGA Research Network (https://www. cancer.gov/tcga). The human cell line authentication, automated DNA sequencing, and molecular imaging were performed in the Vermont Integrative Genomics Resource DNA Facility and was supported by the University of Vermont Cancer Center, Lake Champlain Cancer Research Organization, and the UVM Larner College of Medicine. The research reported here was supported by grant U54 GM115516 from the National Institutes of Health for the Northern New England Clinical and Translational Research network.

\section{Compliance with Ethical Standards}

Conflict of Interest The authors declare that they have no conflict of interest.

\section{References}

1. Bray F, Ferlay J, Soerjomataram I, Siegel RL, Torre LA, Jemal A (2018) Global cancer statistics 2018: GLOBOCAN estimates of incidence and mortality worldwide for 36 cancers in 185 countries. CA Cancer J Clin 68(6):394-424

2. DeSantis C et al (2014) Breast cancer statistics, 2013. CA Cancer J Clin 64(1):52-62

3. Doan TB, Graham JD, Clarke CL (2017) Emerging functional roles of nuclear receptors in breast cancer. J Mol Endocrinol 58(3):R169R190

4. Park JW, Zhao L, Cheng SY (2013) Inhibition of estrogendependent tumorigenesis by the thyroid hormone receptor beta in xenograft models. Am J Cancer Res 3(3):302-311

5. Martinez-Iglesias O et al (2009) Thyroid hormone receptor beta1 acts as a potent suppressor of tumor invasiveness and metastasis. Cancer Res 69(2):501-509

6. Park JW, Zhao L, Willingham M, Cheng SY (2015) Oncogenic mutations of thyroid hormone receptor beta. Oncotarget 6(10): 8115-8131

7. Heublein S, Mayr D, Meindl A, Angele M, Gallwas J, Jeschke U, Ditsch N (2015) Thyroid hormone receptors predict prognosis in BRCA1 associated breast Cancer in opposing ways. PLoS One 10(6):e0127072

8. Gu G, Gelsomino L, Covington KR, Beyer AR, Wang J, Rechoum Y, Huffman K, Carstens R, Andò S, Fuqua SA (2015) Targeting thyroid hormone receptor beta in triple-negative breast cancer. Breast Cancer Res Treat 150(3):535-545

9. Aranda A, Martínez-Iglesias O, Ruiz-Llorente L, García-Carpizo V, Zambrano A (2009) Thyroid receptor: roles in cancer. Trends Endocrinol Metab 20(7):318-324

10. Nielsen SM et al (2016) The breast-thyroid Cancer link: a systematic review and meta-analysis. Cancer Epidemiol Biomark Prev 25(2):231-238 
11. Joseph KR, Edirimanne S, Eslick GD (2015) The association between breast cancer and thyroid cancer: a meta-analysis. Breast Cancer Res Treat 152(1):173-181

12. Bolf EL, Sprague BL, Carr FE (2019) A linkage between thyroid and breast cancer: a common etiology? Cancer Epidemiol Biomark Prev 28(4):643-649

13. An JH, Hwangbo Y, Ahn HY, Keam B, Lee KE, Han W, Park DJ, Park IA, Noh DY, Youn YK, Cho BY, Im SA, Park YJ (2015) A possible association between thyroid cancer and breast cancer. Thyroid 25(12):1330-1338

14. Lee YT (1983) Breast carcinoma: pattern of metastasis at autopsy. J Surg Oncol 23(3):175-180

15. Durante C, Haddy N, Baudin E, Leboulleux S, Hartl D, Travagli JP, Caillou B, Ricard M, Lumbroso JD, De Vathaire F, Schlumberger M (2006) Long-term outcome of 444 patients with distant metastases from papillary and follicular thyroid carcinoma: benefits and limits of radioiodine therapy. J Clin Endocrinol Metab 91(8): 2892-2899

16. Sancisi V, Borettini G, Maramotti S, Ragazzi M, Tamagnini I, Nicoli D, Piana S, Ciarrocchi A (2012) Runx2 isoform I controls a panel of proinvasive genes driving aggressiveness of papillary thyroid carcinomas. J Clin Endocrinol Metab 97(10):E2006-E2015

17. Niu DF, Kondo T, Nakazawa T, Oishi N, Kawasaki T, Mochizuki $\mathrm{K}$, Yamane T, Katoh R (2012) Transcription factor Runx2 is a regulator of epithelial-mesenchymal transition and invasion in thyroid carcinomas. Lab Investig 92(8):1181-1190

18. Gillis NE et al (2018) Thyroid hormone receptor $\beta$ suppression of RUNX2 is mediated by Brahma related gene 1 dependent chromatin remodeling. Endocrinology en.2018-00128-en.2018-00128

19. Carr FE et al (2016) Thyroid hormone receptor-beta (TRbeta) mediates runt-related transcription factor 2 (Runx2) expression in thyroid Cancer cells: a novel signaling pathway in thyroid Cancer. Endocrinology 157(8):3278-3292

20. Ferrari N, McDonald L, Morris JS, Cameron ER, Blyth K (2013) RUNX2 in mammary gland development and breast cancer. J Cell Physiol 228(6): 1137-1142

21. Pande S, Browne G, Padmanabhan S, Zaidi SK, Lian JB, van Wijnen A, Stein JL, Stein GS (2013) Oncogenic cooperation between PI3K/Akt signaling and transcription factor Runx2 promotes the invasive properties of metastatic breast cancer cells. J Cell Physiol 228(8): 1784-1792

22. Pratap J, Javed A, Languino LR, van Wijnen A, Stein JL, Stein GS, Lian JB (2005) The Runx2 osteogenic transcription factor regulates matrix metalloproteinase 9 in bone metastatic cancer cells and controls cell invasion. Mol Cell Biol 25(19):8581-8591

23. Inman CK, Shore P (2003) The osteoblast transcription factor Runx2 is expressed in mammary epithelial cells and mediates osteopontin expression. J Biol Chem 278(49):48684-48689

24. Papachristou DJ, Papachristou GI, Papaefthimiou OA (2005) The MAPK-AP-1/-Runx2 signalling axes are implicated in chondrosarcoma pathobiology either independently or via upregulation of VEGF. Histopathology 47:565-574

25. Sun X, Wei L, Chen Q (2009) HDAC4 represses vascular endothelial growth factor expression in chondrosarcoma by modulating RUNX2 activity. J Biol Chem 284:21881-21890

26. Akech J, Wixted JJ, Bedard K, van der Deen M, Hussain S, Guise TA, van Wijnen A, Stein JL, Languino LR, Altieri DC, Pratap J, Keller E, Stein GS, Lian JB (2010) Runx2 association with progression of prostate cancer in patients: mechanisms mediating bone osteolysis and osteoblastic metastatic lesions. Oncogene 29(6): 811-821

27. Jerzak KJ, Cockburn J, Pond GR, Pritchard KI, Narod SA, DhesyThind SK, Bane A (2015) Thyroid hormone receptor alpha in breast cancer: prognostic and therapeutic implications. Breast Cancer Res Treat 149(1):293-301
28. Kollar A et al (2016) Different types of luciferase reporters show distinct susceptibility to T3-evoked Downregulation. Thyroid 26(1):179-182

29. Wu KK (2006) Analysis of protein-DNA binding by streptavidinagarose pulldown. Methods Mol Biol 338:281-290

30. McDonald L, Ferrari N, Terry A, Bell M, Mohammed ZM, Orange C, Jenkins A, Muller WJ, Gusterson BA, Neil JC, Edwards J, Morris JS, Cameron ER, Blyth K (2014) RUNX2 correlates with subtype-specific breast cancer in a human tissue microarray, and ectopic expression of Runx2 perturbs differentiation in the mouse mammary gland. Dis Model Mech 7(5):525-534

31. Uhlen, M., et al. 2015 Proteomics. Tissue-based map of the human proteome. Science 347(6220): 1260419

32. Gao J et al (2013) Integrative analysis of complex cancer genomics and clinical profiles using the cBioPortal. Sci Signal 6(269):pl1

33. Cerami E, Gao J, Dogrusoz U, Gross BE, Sumer SO, Aksoy BA, Jacobsen A, Byrne CJ, Heuer ML, Larsson E, Antipin Y, Reva B, Goldberg AP, Sander C, Schultz N (2012) The cBio cancer genomics portal: an open platform for exploring multidimensional cancer genomics data. Cancer Discov 2(5):401-404

34. Wu Y, Koenig RJ (2000) Gene regulation by thyroid hormone. Trends Endocrinol Metab 11(6):207-211

35. Strait KA, Zou L, Oppenheimer JH (1992) Beta 1 isoform-specific regulation of a triiodothyronine-induced gene during cerebellar development. Mol Endocrinol (Baltimore, Md.) 6(11):1874-1880

36. Nakajima K, Tazawa I, Yaoita Y (2018) Thyroid hormone receptor $\alpha$ - and $\beta$-knockout Xenopus tropicalis tadpoles reveal subtypespecific roles during development. Endocrinology 159(2):733-743

37. Denver RJ, Ouellet L, Furling D, Kobayashi A, Fujii-Kuriyama Y, Puymirat J (1999) Basic transcription element-binding protein (BTEB) is a thyroid hormone-regulated gene in the developing central nervous system. Evidence for a role in neurite outgrowth. J Biol Chem 274(33):23128-23134

38. Yamada D, Fujikawa K, Kawabe K, Furuta T, Nakada M, Takarada $\mathrm{T}$ (2018) RUNX2 promotes malignant progression in Glioma. Neurochem Res 43(11):2047-2054

39. Park JW, Zhao L, Willingham M, Cheng SY (2015) Oncogenic mutations of thyroid hormone receptor $\beta$. Oncotarget 6(10):81158131

40. Garcia-Silva S, Aranda A (2004) The thyroid hormone receptor is a suppressor of ras-mediated transcription, proliferation, and transformation. Mol Cell Biol 24(17):7514-7523

41. Martinez-Iglesias $\mathrm{O}$ et al (2009) Thyroid hormone receptor $\beta 1$ acts as a potent suppressor of tumor invasiveness and metastasis. Cancer Res:501-509

42. Kim WG, Zhao L, Kim DW, Willingham MC, Cheng SY (2014) Inhibition of tumorigenesis by the thyroid hormone receptor beta in xenograft models. Thyroid 24(2):260-269

43. Altieri DC, Languino LR, Lian JB, Stein JL, Leav I, van Wijnen A, Jiang Z, Stein GS (2009) Prostate cancer regulatory networks. J Cell Biochem 107(5):845-852

44. Cao $\mathrm{Z}$ et al (2017) The expression and functional significance of Runx 2 in hepatocellular carcinoma: its role in vasculogenic mimicry and epithelial-mesenchymal transition. Int J Mol Sci 18(3)

45. Sase $\mathrm{T}$ et al (2012) Runt-related transcription factor 2 in human colon carcinoma: a potent prognostic factor associated with estrogen receptor. Int J Cancer 131(10):2284-2293

46. Boregowda RK, Olabisi OO, Abushahba W, Jeong BS, Haenssen KK, Chen W, Chekmareva M, Lasfar A, Foran DJ, Goydos JS, Cohen-Solal KA (2014) RUNX2 is overexpressed in melanoma cells and mediates their migration and invasion. Cancer Lett 348(1-2):61-70

47. Cicatiello AG, Ambrosio R, Dentice M (2017) Thyroid hormone promotes differentiation of colon cancer stem cells. Mol Cell Endocrinol 459:84-89 
48. Sisley K et al (1993) Loss of heterozygosity of the thyroid hormone receptor B in posterior uveal melanoma. Melanoma Res:457-461

49. Alamino VA, Mascanfroni ID, Montesinos MM, Gigena N, Donadio AC, Blidner AG, Milotich SI, Cheng SY, Masini-Repiso AM, Rabinovich GA, Pellizas CG (2015) Antitumor responses stimulated by dendritic cells are improved by Triiodothyronine binding to the thyroid hormone receptor beta. Cancer Res 75(7): $1265-1274$

50. Webb P (2004) Selective activators of thyroid hormone receptors. Expert Opin Investig Drugs 13(5):489-500

51. Lin HY, Glinsky GV, Mousa SA, Davis PJ (2015) Thyroid hormone and anti-apoptosis in tumor cells. Oncotarget 6(17):14735-14743

52. Davis PJ, Goglia F, Leonard JL (2016) Nongenomic actions of thyroid hormone. Nat Rev Endocrinol 12(2):111-121

53. Gupta A, Cao W, Chellaiah MA (2012) Integrin alphavbeta3 and CD44 pathways in metastatic prostate cancer cells support osteoclastogenesis via a Runx2/Smad 5/receptor activator of NF-kappaB ligand signaling axis. Mol Cancer 11:66
54. Dai Z, Guo F, Wu F, Xu H, Yang C, Li J, Liang P, Zhang H, Qu L, Tan Y, Wan Y, Li Y (2014) Integrin alphavbeta3 mediates the synergetic regulation of core-binding factor alpha1 transcriptional activity by gravity and insulin-like growth factor-1 through phosphoinositide 3-kinase signaling. Bone 69:126-132

55. Chiellini G, Apriletti JW, Yoshihara HA, Baxter JD, Ribeiro RC, Scanlan TS (1998) A high-affinity subtype-selective agonist ligand for the thyroid hormone receptor. Chem Biol 5(6):299-306

56. Ye L, Li YL, Mellström K, Mellin C, Bladh LG, Koehler K, Garg N, Garcia Collazo AM, Litten C, Husman B, Persson K, Ljunggren J, Grover G, Sleph PG, George R, Malm J (2003) Thyroid receptor ligands. 1. Agonist ligands selective for the thyroid receptor beta1. J Med Chem 46(9):1580-1588

Publisher's Note Springer Nature remains neutral with regard to jurisdictional claims in published maps and institutional affiliations. 